\title{
Peran Abdul Haris Nasution dalam Pembebasan Irian Barat (1957-1962)
}

\author{
Devi Nurhikmi, Ajid Thohir, Samsudin \\ Fakultas Adab dan Humaniora \\ Universitas Islam Negeri Sunan Gunung Djati Bandung \\ Email: devinurhikmi45@gmail.com
}

\begin{abstract}
This article seeks to describe one of the Dutch-Indonesian conflict, the liberation of West Irian. The focus of this study is the role of Abdul Haris Nasution in the Liberation of West Irian in 1957-1962. The method used in this study is historical research method which is carried out through four stages: heuristic, criticism, interpretation, and historiography. Abdul Haris Nasution's role in this event was taking over Dutch companies, establishing the National Front for the Liberation of West Irian (FNPIB) and becoming its chairman, also TNI diplomacy by buying weapons and mision abroad to hear other countries' responses regarding West Irian.
\end{abstract}

Keyword: Military Policy, Conflict, rebellion 


\section{Pendahuluan}

Konferensi Meja Bundar (KMB) yang dilaksanakan di Belanda tahun 1949 sebagai platfrom perjuangan rakyat Indonesia menuntut janji Belanda menyerahkan kedaulatan dengan sungguh, penuh, dan tidak bersyarat pada bangsa Indonesia menghasilkan tiga perundingan. Pertama, pada 27 Desember 1949 akan dilaksanakan penyerahan kedaulatan kepada Republik Indonesia Serikat. Kedua, APRIS adalah satu-satunya organisasi kesenjataan RIS. Ketiga, Irian Barat (sekarang Papua) akan dibicarakan kembali setahun kemudian. ${ }^{1}$ Akan tetapi KMB tidak berhasil menyelesaikan salah satu masalah yaitu penyerahan kekuasaan oleh Kerajaan Belanda atas Irian Barat. Setelah setahun, Irian Barat masih tetap dikuasai oleh Belanda. ${ }^{2}$

Perundingan Bilateral mengenai penyerahan Irian Barat kepada Indonesia memang dilakukan tetapi tidak ada hasilnya karena Belanda selalu menghindar atau mempersulit. Sepanjang tahun 1950-an, Belanda tetap bersikeras bercokol di Irian Barat. Bagi Belanda, wilayah ini dianggap sebagai simbol sisa kebanggaannya sebagai bekas kekuasaan kolonial yang besar. Bahkan sejak 1954, Belanda menutup pintu rapat-rapat, menolak untuk merundingkan masalah tinggalan KMB itu dengan Indonesia. ${ }^{3}$ Sejarah perjuangan bangsa Indonesia tidak akan terlepas dari pelaku sejarah yang memiliki peran penting dalam membangun bangsa. Salah satunya adalah Abdul Haris Nasution yang berjasa terhadap Pembebasan Irian Barat.

Pembahasan tentang Peran A. Nasution dalam Pembebasan Irian Barat bukan hal yang baru. Sebelumnya sudah ada namun tidak spesifik, lengkap, dan kronologis. Pertama, buku dari Dinas Sejarah Angkatan Darat, Biografi Jenderal Besar DR. A. Nasution: Perjalanan Hidup dan Pengabdiannya (CV. Abadi, 2009). Buku ini membahas seluruh perjalanan hidup seorang Jenderal Besar A. Nasution. Salah satu bagian buku bagian buku ini menjelaskan peranan A. Naution dalam membantu Presiden yaitu misi Pembebasan Irian Barat. Namun, buku ini hanya mejelaskan secara singkat. Penelitian yang penulis lakukan mencoba mengungkap peristiwa yang terjadi secara lengkap dan kronologis. Kedua, Skripsi Muisah Farhani Lubis,

\footnotetext{
${ }^{1}$ Ahmad Mansur Suryanegara, Api Sejarah 2 (Bandung: Surya Dinasti, 2016), 280.

2 Marwati Djoened Poesponegoro dan Nugroho Notosusanto, Sejarah Nasional Indonesia VI (Jakarta: Balai Pustaka, 1990), 331.

${ }^{3}$ Beny Adrian, 52 Tahun Infiltrasi PGT di Irian Barat (Jakarta: Gramedia, 2014), 2.
} 
Peranan Abdul Haris Nasution pada masa Orde Lama (Medan: Universitas Negeri Medan, 2013). Skripsi ini membahas peranan A. Nasution di masa Orde Lama dengan menduduki berbagai jabatan politik dan militer. Penelitian ini secara khusus membahas peranannya dalam politik kabinet misi Pembebasan Irian Barat. Dari tinjauan diatas, penulis mengambil kesimpulan bahwa penelitian mengenai Peranan A. Nasution dalam Pembebasan Irian Barat (1957-1962) secara kronologis, utuh, dan lengkap belum ada yang membahas. Artikel ini berusaha melengkapi penelitian yang sudah ada. Penulis juga berusaha untuk mengumpulkan beberapa informasi yang didapat dari berbagai sumber sehingga menjadi satu kesatuan yang sistematis.

\section{Metode Penelitian}

Penelitian ini dilakukan dengan menggunakan metode penelitian sejara Penelitian sejarah merupakan penelitian yang tergolong "metode historis" yaitu metode penelitian yang khusus digunakan dalam penelitian sejarah melalui tahapan tertentu. Penerapan ini sebagaimana yang dikemukakan oleh Notosusanto yaitu heuristik, kritik, interpretasi, dan historiografi. ${ }^{4}$

Heuristik adalah kegiatan mencari sumber untuk mendapatkan datadata atau materi sejarah atau evidensi sejara ${ }^{5}$ Adapun cara yang ditempuh oleh penulis dalam menghimpun data-data sumber sejarah adalah dengan menemukan sumber-sumber tertulis dan arsip yang diperoleh melalui studi kepustakaan dan media. Sumber primer yang didapat penulis yaitu buku A. Nasution, Memenuhi Panggilan Tugas Jilid 1: Kenangan Masa Muda, Jilid 4: Masa Pancaroba 2, Jilid 5: Kenangan Masa Orde Lama. Beberapa buku dan arsip dari Dinas Sejarah TNI AD Bandung seperti Dokumen, buku, maupun arsip-arsip kebijakan pemerintah tentang Pembebasan Irian Barat. Arsip juga didapatkan dari situs Delpher Belanda yaitu berupa koran Algemeen Handelsblad, Friese Koerir, dan Nieuw Guinea Koerier.

Kritik yaitu verifikasi atau keabsahan sumber. ${ }^{6}$ Pada tahap ini, oleh penulis sumber dikumpulkan dalam kegiatan heuristik yang berupa bukubuku yang relevan dengan pembahasan yang terkait, ataupun hasil temuan di lapangan tentang bukti-bukti pembahasan atau topik utama penelitian.

\footnotetext{
${ }^{4}$ Beny Adrian, 52 Tahun Infiltrasi PGT di Irian Barat 75.

${ }^{5}$ Beny Adrian, 52 Tahun Infiltrasi PGT di Irian Barat 93..

${ }^{6}$ Kuntowijoyo, Pengantar Ilmu Sejarah (Yogyakarta: Penerbit Tara Wacana, 2013), 77.
} 
Selanjutnya diseleksi dengan mengacu pada prosedur yang ada, yakni sumber yang faktual dan orisinalnya terjamin. ${ }^{7}$ Penulis menggunakan kritik ekstren dan kritik intern.

Interpretasi atau penafsiran sejarah, menurut Kuntowijoyo, sering disebut dengan analisis sejara ${ }^{8}$ Pada tahap ini penulis menggunakan teori "Orang Besar" dan teori sosiologi "Status dan Peran." Sedangkan Historiografi adalah proses penyusunan fakta sejarah dan berbagai sumber yang telah diseleksi dalam bentuk penulisan sejara ${ }^{9}$

\section{Hasil dan Pembahasan}

\section{Biografi dan Posisi Abdul Haris Nasution dalam Politik Kabinet Misi Pembebasan Irian Barat}

Jenderal TNI (Purn.) Dr. Abdul Haris Nasution atau A. Nasution lahir di desa Hutapungkut, Distrik Mandailing, Kecamatan Kotanopan, Tapanuli Selatan, Sumatera Utara pada akhir Perang Dunia I tanggal 3 Desember 1918 pukul 08.00 pagi. ${ }^{10}$ Dia berasal dari keluarga pedagang. Ayahnya termasuk pedagang tekstil, kelontong, atau mengumpulkan karet dan kopi yang kemudian dijual kepada para pedagang Cina di Padang Sidempuan, Sibolga, Bukit Tinggi maupun Padang. ${ }^{11}$

Distrik Mandailing termasuk salah satu pojok Indonesia yang terdahulu dimasuki Islam dan didatangi pedagang-pedagang Eropa disamping pelabuhan-pelabuhan lain pantai Barat Sumatera seperti Barus dan Airbangis. ${ }^{12}$ Distrik ini juga terkenal sebagai pelopor pergerakan politik di masa kolonial. Di masa kebangkitan nasional telah ada Sarekat Islam. Pergerakan nasional meningkat di awal tahun 30-an di Tapanuli dengan dipelopori pemuda-pemuda Hutapungkut yang menyebabkan tiga orang dibuang dan diinternir pemerintah kolonial Belanda di Boven Digul. Pada tahun 1929 oleh pemuda-pemuda didirikan perkumpulan sosial bernama

${ }^{7}$ Sulasman. 2014. Metodologi Penelitian Sejara Bandung: Pustaka Setia. 101.

${ }^{8}$ Sulasman. 2014. Metodologi Penelitian Sejarah. 111.

9 Sulasman. 2014. Metodologi Penelitian Sejara 147.

${ }^{10}$ Dinas Sejarah Angkatan Darat, Biografi Jenderal Besar DR. A. Nasution: Perjalanan Hidup dan Pengabdiannya (Dinas Sejarah Angkatan Darat, 2009), 39.

${ }^{11}$ Dinas Sejarah Angkatan Darat, Biografi Jenderal Besar DR. A. Nasution: Perjalanan Hidup dan Pengabdiannya 15.

12 Abdul Haris Nasution, Memenuhi Panggilan Tugas Jilid 1: Kenangan Masa Muda (Jakarta: PT. Gunung Agung, 1984), 1. 
Peran Abdul Haris Nasution dalam Pembebasan Irian Barat (1957-1962)| Devi Nurhikmi, Ajid Thohir, dan Samsudin

"Siala-Sampagul" yang bertujuan untuk tolong menolong, pemberantasan buta huruf, serta mengadakan taman pembacaan. Surat-surat kabar dilanggani dan dibaca secara luas. ${ }^{13}$ Pengurus partai-partai lahir dari perkumpulan ini. Karena itu kampung ini menjadi sasaran intel kolonial. ${ }^{14}$

Dia bersekolah di Hollands Inlandse School (HIS) Kotanopan dan mendapat gemblengan batin untuk mencintai tanah air melalui cerita-cerita rakyat dan kisah para Nabi yang menekankan pentingnya pembelaan pada tanah air. ${ }^{15}$ Pada tahun 1932, dia selesai sekolah HIS dan seterusnya diterima menjadi siswa di Sekolah Raja, Hollands Inlandse Kweekschool (HIK) Sekolah Guru di .Bukit Tinggi dan pindah ke HIK Bandung. Sekolah ini sering digunakan untuk rapat atau kongres organisasi-organisasi pergerakan. ${ }^{16}$ Perhatiannya pada pelajaran sejarah pun tidak beruba Guru sejarahnya bernama Van der Werf yang juga Ketua Partai Katolik di Bandung. Dari Werf itu, dia menimba pengetahuan sejarah dan politik karena selain menguraikan materi sejarah, guru Belanda itu juga banyak bercerita tentang masalah politik. Dari hari ke hari, minatnya pada politik kian meningkat. Sebaliknya keinginan untuk menjadi guru perlahan-lahan sirna. Pada tahun 1938, dia menyelesaikan studinya di Bandung untuk kemudian mengikuti ujian akhir AMS/B sebagai Extranei di Jakarta. Dia lulus sebagai otodidak 4 mata pelajaran di luar kurikulum HIK. ${ }^{17}$

Pada tahun 1938, dia melaksanakan tugas mengajar di Bengkulu. Dia tinggal di dekat rumah Soekarno yang saat itu tengah menjalani pengasingan. Dari sinilah kemudian dia bisa menjalin kontak langsung dengan Soekarno. Setahun kemudian, dia pindah ke Tanjungpraja, dekat Palembang untuk melanjutkan tugas mengajarnya. Di tempat baru itulah hasrat politik dan militernya semakin kuat. Dari sinilah perjalanan hidup A. Nasution berubah dari seorang guru menjadi politisi dan militer. ${ }^{18}$

Muda. 6.

${ }^{13}$ Abdul Haris Nasution, Memenuhi Panggilan Tugas Jilid 1: Kenangan Masa Muda. 7.

${ }^{14}$ Abdul Haris Nasution, Memenuhi Panggilan Tugas Jilid 1: Kenangan Masa

15 Dinas Sejarah Angkatan Darat, Biografi Jenderal Besar DR. A. Nasution:

Perjalanan Hidup dan Pengabdiannya. 15-17.

${ }^{16}$ Dinas Sejarah Angkatan Darat, Biografi Jenderal Besar DR. A. Nasution:

Perjalanan Hidup dan Pengabdianny 18-19.

${ }^{17}$ Dinas Sejarah Angkatan Darat, Biografi Jenderal Besar DR. A. Nasution:

Perjalanan Hidup dan Pengabdianny 19-20.

${ }^{18}$ Lukman Santoso Az, Jenderal-jenderal yang Mempengaruhi Sejarah Dunia (Yogyakarta: Penerbit Palapa, 2014), 17-18. 
Sebagai konsekuensi Jerman menduduki Belanda, Belanda membentuk korps perwira cadangan pada tahun 1940. A. Nasution ikut bergabung dan dikirim ke Akademi Militer Bandung untuk menjalani serangkaian pelatihan. Dari sinilah dia mendapatkan kepangkatan militer. ${ }^{19}$ Ketika Indonesia telah berada di bawah kekuasaan Jepang, dia membantu organisasi PETA sebagai pembawa pesan (kurir). Setelah itu, berturut-turut dia menjabat Pegawai Kotapraja Bandung, Wakil Komandan Batalyon Pelopor 1, Anggota Angkatan Muda di Bandung, ${ }^{20}$ berkarier di TKR, Panglima Divisi I Siliwangi Jawa Barat, Panglima Komandan Jawa, sampai diangkat menjadi KSAD. Walaupun antara tahun 1952 hingga 1955 sempat non-aktif dan menulis pengalamannya menjadi buku, sejak 1955, dia diangkat kembali menjadi KSAD. ${ }^{21}$ Dari sini, kariernya dalam militer maupun politik terus meningkat. Kemudian Sejak 1972, dia pensiun dan berhenti dari semua tugas resmi RI dan ABRI. ${ }^{22}$ Atas jasa-jasanya dalam militer, dia mendapatkan banyak sekali Bintang-bintang, Kehormatan, Satyalencana, Keanggotaan Kehormatan, dan beberapa Gelar Kehormatan dari dalam negeri maupun luar negeri. Di masa tuanya, dia sempat dibelit persoalan. Namun setelah 21 tahun dikucilkan, tiba-tiba dia dirangkul lagi oleh Soeharto dan dianugerahi pangkat Jenderal Besar Bintang Lima. Dia meninggal pada 6 September 2000 pukul 07.30 WIB di Rumah Sakit Angkatan Darat Gatot Subroto Jakarta setelah lama menderita stroke dan dimakamkan di Taman Makam Pahlawan Kalibata. ${ }^{23}$

Posisinya dalam kabinet terkait Pembebasan Irian Barat, yaitu Kabinet "Karya" Djuanda (1957-1959) sebagai Kepala Staf Angkatan Darat (KSAD), ${ }^{24}$ Kabinet Kerja I (1959-1960) menjadi Menteri Keamanan

${ }^{19}$ Dinas Sejarah Angkatan Darat, Biografi Jenderal Besar DR. A. Nasution: Perjalanan Hidup dan Pengabdianny 19-20.

${ }^{20}$ Abdul Haris Nasution, Bisikan Nurani Seorang Jenderal: Kumpulan Wawancara dengan Media Massa, ed. oleh Drs. Bakri A. G. Tianlean (Bandung: Penerbit Mizan, 1997), 3.

21 Abdul Haris Nasution, Bisikan Nurani Seorang Jenderal: Kumpulan Wawancara dengan Media Massa, ed. oleh Drs. Bakri A. G. Tianlean 3. 4.

${ }^{22}$ Abdul Haris Nasution, Bisikan Nurani Seorang Jenderal: Kumpulan Wawancara dengan Media Massa, ed. oleh Drs. Bakri A. G. Tianlean 3-5

${ }^{23}$ Tim Narasi, 100 Tokoh yang Mengubah Indonesia (Yogyakarta: Penerbit Narasi, 2009), 5.

${ }^{24}$ P. N. Simanjuntak, Kabinet-kabinet Republik Indonesia dari Awal Kemerdekaan sampai Reformasi (Jakarta: Djambatan, 2003), 189. 
Pertahanan dan merangkap menjadi KSAD, ${ }^{25}$ Kabinet Kerja II (1960-1962) terdaftar sebagai Menteri Keamanan Nasional serta KSAD, ${ }^{26}$ dan Kabinet Kerja III (1962-1963) menduduki Wakil Menteri Pertama sebagai Koordinator dalam Bidang Pertahanan dan Keamanan serta masih menjadi $\mathrm{KSAD}^{27}$

\section{Peran Abdul Haris Nasution dalam Pembebasan Irian Barat (1957- 1962)}

\section{Pengambilalihan Perusahaan Belanda}

Sejak tahun 1954-1957 perjuangan diplomasi Indonesia tentang Irian Barat tidak pernah memperoleh dukungan $2 / 3$ suara dalam sidang PBB, Belanda ingin memberikan hak menentukan nasib sendiri kepada rakyat Irian Barat sesuai dengan isi Piagam PBB. ${ }^{28}$ Tindakan Indonesia memang menjadi radikal setelah kegagalan rancangan resolusi tentang masalah Irian Barat pada Sidang Umum ke 12 PBB tahun 1957 itu. Tindakan radikal itu ialah pada tanggal 2 Desember 1957, semua perusahaan Belanda dioper oleh Kepala Staf Angkatan Darat selaku Penguasa Perang Pusat (Peperpu) yang disahkan kemudian dengan nasionalisasi melalui UU No. 86 tahun 1958 yang antara lain mengatur hak ganti rugi bagi pemilik perusahaanperusahaan Belanda. Suatu panitia yang ditunjuk oleh Pemerintah Indonesia akan melakukan penaksiran dan penerapan besarnya jumlah ganti rugi tersebut, dengan seperlunya naik banding ke Mahkamah Agung sebagai instansi terakhir. ${ }^{29}$ Adapun kebijakan ini diatur kemudian dalam UU No. 86 Tahun 1958 tentang Nasionalisasi Perusahaan-perusahan Milik Belanda di Indonesia. ${ }^{30}$ Juga diatur mengenai pelaksanaan nasionalisasi perusahaanperusahaan Belanda yang bermodal campuran Belanda dan asing lain, menjadi modal campuran Indonesia dan asing lain, untuk menutup sama sekali kemungkinan pemindahan laba perusahaan mengalir ke negeri

\footnotetext{
${ }^{25}$ P. N. Simanjuntak, Kabinet-kabinet Republik Indonesia dari Awal Kemerdekaan sampai Reformasi 201.

${ }^{26}$ P. N. Simanjuntak, 208-209.

${ }^{27}$ P. N. Simanjuntak,. 229-230.

${ }^{28}$ Dinas Sejarah Angkatan Darat, Op cit., 93-94.

${ }^{29}$ Abdul Haris Nasution, Memenuhi Panggilan Tugas Jilid 5: Kenangan Masa Orde Lama, I (Jakarta: PT. Gunung Agung, 1985), 282.

${ }^{30}$ Markas Besar Angkatan Darat Dinas Sejarah, Sejarah Perjuangan Trikora, (Dinas Sejarah Angkatan Darat, 2018), 17-18.
} 
Peran Abdul Haris Nasution dalam Pembebasan Irian Barat (1957-1962)| Devi Nurhikmi, Ajid Thohir, dan Samsudin

Belanda yang diatur melalui Keputusan Menteri Pertama RI No. 485/MP/1959 tanggal 17 September $1959 .{ }^{31}$

\section{Mendirikan Front Nasional Pembebasan Irian Barat (FNPIB) dan Menjadi Ketuanya}

Untuk meningkatkan aksi-aksi Pembebasan Irian Barat maka dibentuklah Front Nasional Pembebasan Irian Barat (FNPIB) yang dibentuk dan diketuai oleh KSAD A. Nasution dan mempunyai organisasi dari tingkat pusat sampai ke daera ${ }^{32}$ Organisasi ini disusun kebawah mulai dari tingkat Pusat, Swatantra tingkat I, dan Swatantra tingkat II. ${ }^{33}$

Perjuangan Irian Barat pada akhirnya ditentukan oleh perjuangan di dalam negeri, luar negeri, dan di wilayah Irian Barat sendiri baik militer, politis, maupun ekonomis. Khusus pembangunan kekuatan dalam negeri terutama pemerintah menugaskan FNPIB yang dapat digunakan oleh pemerintah baik untuk usaha diplomasi, maupun eventual untuk militer. ${ }^{34}$ Front Nasional Pembebasan Irian Barat (FNPIB) atau disingkat Front Nasional ini didirikan oleh A. Nasution dengan Keputusan Penguasa Perang Pusat No. Kpts/Peperpu/0345/1958 dan sekaligus menjadikannya sebagai Ketua Umum. Front Nasional ini adalah badan semi resmi yang membantu dan mendorong segala usaha kegiatan Pemerintah pada umumnya dan Penguasa Perang pada khususnya dalam rangka perjuangan mengembalikan Irian Barat ke dalam wilayah kekuasaan Republik Indonesia. Badan ini memang dibentuk sebagai tugas konfrontasi yang diketuai oleh A. Nasution sebagai Kepala Staf Angkatan Darat (KSAD) atau Penguasa Perang Pusat (Perperpu). Seluruh golongan karya terorganisasi melalui Badan Kerja Sama: pemuda, petani, buruh, ulama, dan lainnya ikut didalamnya. ${ }^{35}$

\section{Diplomasi TNI}

${ }^{31}$ Keputusan Menteri Pertama RI No.485/MP/1959, Ketentuan-ketentuan tentang Kebijaksanaan Pemerintah terhadap Perusahaan-perusahaan milik Belanda (Jakarta, 1959).

${ }^{32}$ Markas Besar TNI, Pusat Sejarah, dan Tradisi TNI, Sejarah TNI Jilid 3 19601965 (Jakarta: Markas Besar TNI, Pusat Sejarah, dan Tradisi TNI, 2000), 112.

${ }^{33}$ Kepala Staf Angkatan Darat/Penguasa Perang Pusat/Ketua Umum FNPIB Pusat A. Nasution, Keputusan Penguasa Perang Pusat No. Kpts/Peperpu/0345/1958 tentang Peraturan Rumah Tangga Front Nasional Pembebasan Irian Barat (Jakarta, 1959), 1-5.

${ }^{34}$ Abdul Haris Nasution, Memenuhi Panggilan Tugas Jilid 5: Kenangan Masa Orde Lama, I (Jakarta: PT. Gunung Agung, 1985), 81.

${ }^{35}$ Nasution. 76. 
Selain membentuk FNPIB, A. Nasution terbang ke Washington untuk melakukan kunjungan bersama Wakil KSAD Gatot Subroto ke Menteri Pertahanan, Menteri Luar Negeri, KSAD, KSAL, KSAU, dan Menteri AD Amerika. Dia menjelaskan sasaran utamanya yaitu memperoleh persanjataan ofensif namun Wakil Menteri Luar Negeri Amerika Jenderal Stilwell tidak memberikan jawaban yang tegas menolak tetapi hanya dijelaskan prosedurprosedur yang berlaku guna pemberian senjata pada sekutu-sekutunya dan bukan sekutu seperti indonesia. Menurut mereka, senjata dan alat-alat yang A. Nasution maksud adalah soal politik yang mana digarap dengan Departemen Luar Negeri dan Senat. Jelas bahwa tak mungkin Indonesia mendapat senjata dari Amerika. Dari pembicaraan ini dapat disimpulkan bahwa Amerika terikat pada persekutuannya dengan Belanda. Demikianlah dalam pembebasan Irian Barat itu timbul Diplomasi TNI dan konklusi yang diperoleh dari sikap Amerika dalam hal persenjataan memaksa Indonesia membuka diplomasi dengan Blok Timur atau Uni Soviet. ${ }^{36}$

Minggu ketiga bulan Februari 1960, Indonesia sedang menerima kunjungan Nikita Khrushchev, Perdana Menteri Uni Soviet. ${ }^{37}$ Kedatangannya membawa perundingan-perundingan kedua belah pihak dan A. Nasution sendiri beberapa kali ikut mendampingi Presiden Soekarno. ${ }^{38}$ Pada pertemuan ini, secara umum disinggung kemungkinan keperluan militer. ${ }^{39}$ Hal ini disambut baik oleh A. Nasution. Dia yakin bahwa Irian Barat akan dimenangkan oleh Indonesia dari Belanda secara militer, politik, dan diplomasi. Menurutnya, dasar pertempuran adalah pertumbuhan kekuatan internal. Kekuatan ini dapat digunakan oleh pemerintah di bidang politik dan militer. ${ }^{40}$

Mula-mula ditingkat politik diambil keputusan untuk mencari peralatan dari Uni Soviet. Beberapa negara komunis memang telah bersedia menyerahkan senjata yang Indonesia minta. Namun dalam rapat di Staf Umum Angkatan Darat (SUAD) ternyata pemerintah belum sependapat agar

\footnotetext{
${ }^{36}$ Abdul Haris Nasution, 408-411.

${ }^{37}$ Abdul Haris Nasution, 48

${ }^{38}$ Abdul Haris Nasution, 49.

${ }^{39}$ Abdul Haris Nasution, 49.. 51.

40 "Nasution over Nieuw Guinea," Friese Koerir, 29 Februari 1960, 2.
} 
secara bulat mengambil persenjataan dari Uni Soviet. ${ }^{41}$ Akhirnya ditentukan peralatan tertentu yang diambil dari sana.

Pada akhir November atau awal Desember 1960, A. Nasution dipanggil ke Istana oleh Presiden. Presiden mengutusnya untuk ke Moskow dalam rangka pembelian senjata. ${ }^{42}$ Sebenarnya sebelum ini, Indonesia dua kali mengirimkan delegasinya yaitu Deputi KSAD Kolonel Mokoginta dan Letnan Kolonel Hartawan namun tidak ada perkembangan. ${ }^{43}$ Akhir Desember, dia terbang bersama Menteri Luar Negeri dan KSAU beserta staf dari $\mathrm{AD}, \mathrm{AL}$, dan $\mathrm{AU} .{ }^{44}$ Acara pertama dengan seluruh delegasi berkunjung ke PM Kruschev di Kremlin. Disana terjadi kontrak yang seluruhnya berjumlah setengah miliar dollar Amerika. ${ }^{45}$ Setelah penandatanganan persetujuan kontrak pembelian senjata yang dimuat pula pendidikan perwiraperwira Indonesia untuk operasional dan untuk pemeliharaan alat-alatnya maka diadakan resepsi oleh PM Kruschev. Setelah selesai, A. Nasution berkemas untuk berangkat dengan ajudannya karena esok paginya punya acara di New Delhi. ${ }^{46}$

Sekembalinya A. Nasution dari Uni Soviet, Jenderal Hidayat meneliti kontrak-kontrak yang ada dan mengecek kebutuhan-kebutuhan Angkatan Laut dan Angkatan Udara. Ternyata perlu penambahan-penambahan untuk lebih lengkapnya. Jenderal Hidayat kemudian bertolak ke Moskow untuk hal-hal itu dan mempersiapkan kunjungan A. Nasution yang kedua guna kontrak kedua mengenai kelengkapan pertahanan udara nasional. ${ }^{47}$

Bulan Juni 1961, A. Nasution ke Moskow untuk penandatanganan kontrak kedua. Pertama, A. Nasution bertolak dari Jakarta ke Kairo dimana sedang terjadi pertemuan mempersiapkan Konferensi Non-blok yang akan datang di Beograd. Disana juga diadakan pertemuan dengan pemerintah Aljazair di kediaman Duta Besar Sanusi Harjadinata. Dari Aljazair diutus Menteri Muhammed, Menteri Persenjataan Kolonel Bussuf, dan Duta Besar Ibrahimi. Pertemuan ini untuk menambahkan keperluan Aljazair dalam

${ }^{41}$ Abdul Haris Nasution, Memenuhi Panggilan Tugas Jilid 5: Kenangan Masa Orde Lama, 1985, hlm. 50.

42 Abdul Haris Nasution. 51.

43 Abdul Haris Nasution. 49.

${ }^{44}$ Abdul Haris Nasution

45 Abdul Haris Nasution. 57.

46 Abdul Haris Nasution. 61.

47 Abdul Haris Nasution. 125. 
pembelian senjata ke Moskow. Pembelian senjata ini penting untuk Aljazair dalam upayanya melawan Prancis. ${ }^{48}$

Sehari setelah mendarat di Moskow, dilakukanlah penandatanganan kontrak pembelian senjata yang kedua di Kremlin bersama Marsekal Malinovsky yang juga dihadiri Presiden Soekarno, Presiden Uni Soviet, dan Perdana Menterinya. Sebelumnya dalam pertemuan di Kamar Kerja Perdana Menteri Kruschev, A. Nasution meminta izin kepada kedua pihak agar boleh menggunakan kredit RI untuk pembelian alat-alat bagi Aljazair sebanyak 10 juta dollar dan disetujui. ${ }^{49}$

Pada tahun 1960-1961, A. Nasution melakukan kunjungan ke negaranegara Barat, Timur, dan non-Blok. Misi A. Nasution ini pun tertera dalam laporan bulanan Front Nasional Pembebasan Irian Barat Pusat BKS Khusus B1. IX-158 bahwa perjalanan Menteri Keamanan Nasional ke luar negeri ini mempunyai arti yang penting dan dirangkaikan dengan misi Presiden Soekarno ke PBB. Perjalanan Soekarno ini disempurnakan dan diperkuat oleh perjalanan Menteri Keamanan Nasional. ${ }^{50}$

Misi ke India dan Pakistan dilakukan sesaat setelah pembelian senjata yang pertama. Kedatangan A. Nasution ke India adalah tugas misi politik dan militer. Tugas misi politik dengan Perdana Menteri Nehru yang juga Menteri Luar Negeri. Dia menegaskan di Kementerian Pertahanan bahwa pembebasan Irian Barat dilakukan melalui diplomasi, tetapi jika tidak berhasil maka kemungkinannya akan timbul perang. Bahkan suatu insiden di perairan Irian Barat bisa saja setiap waktu meledakan peperangan dengan Belanda. Dia mengharapkan pemerintah India agar membantu Indonesia seperti ketika masa perang kemerdekaan 1945-1949. India harus melarang pesawat dan kapal Belanda melewati wilayah India jika terjadi perang. Perdana Menteri Nehru membenarkan klaim Indonesia atas Irian Barat tetapi dia meminta dengan sangat agar Indonesia menghindari perang karena perang akan membawa banyak hal yang berbahaya. ${ }^{51}$

A. Nasution bertolak ke Karachi, Pakistan. Dia disambut oleh Menteri Pertahanan Laksamana Khan. Dalam kunjungannya kali ini, dia meminta

\footnotetext{
48 Abdul Haris Nasution. 128.

49 Abdul Haris Nasution. 129.

${ }^{50}$ Front Nasional Pembebasan Irian Barat Pusat BKS Khusus, Laporan Bulanan B1. IX-158, 1960, 6.

${ }^{51}$ Abdul Haris Nasution, Memenuhi Panggilan Tugas Jilid 5: Kenangan Masa Orde Lama. 1985, 64.
} 
agar Pakistan melarang pesawat-pesawat Belanda melewati Pakistan jika terjadi perang. Presiden Ayub Khan dengan tegas mendukung politik Pembebasan Irian Barat. ${ }^{52}$ Setelah selesai acara kunjungan, A. Nasution bertolak ke Singapura dan bermalam di rumah Konsul Jenderal Sugiharto. Barulah besoknya ke Jakarta. Di Kemayoran, masyarakat telah menunggu dan menyambut. Rupanya ada pengerahan masa dalam rangka konfrontasi Pembebasan Irian Barat. Misinya ke Moskow, India, dan Pakistan pun disebut "misi konfontasi" yang oleh pemerintah dibuatkan sekaligus sebagai pengobaran semangat. ${ }^{53}$

Misi konfrontasi selanjutnya, A. Nasution merencanakan dua perjalanan ke luar negeri. Pertama, ke Australia, Selandia Baru, Filipina, dan Thailand sebagai negara SEATO. Kedua, ke Jerman, Prancis, dan Inggris yang dia sambungkan pada kunjungan ke Moskow, Yugoslavia dan Mesir. ${ }^{54}$ Bulan April 1961, dia bertolak ke Australia bersama KSAL Martadinata, Kolonel Sumarsono, Kolonel Supardi, Panglima Nusa Tenggara yang paling dekat dengan Australia dan Mayor Rujito dari BKS Khusus yang bertugas di bidang perjuangan Irian Barat. Kemudian Suska dari Deputi Menteri Luar Negeri. ${ }^{55}$ Mereka tiba di Sidney tanggal 18 April 1961 dan A. Nasution sendiri memberikan presentasi penuh kepada beberapa kabinet Australia mengenai kebijakan Indonesia tentang urusan dalam negeri dan masalah Irian. Pada konferensi pers ini, dia mengatakan bahwa dia akan mendesak Australia untuk memberikan jawaban yang jelas atas pertanyaan tentang posisi apa yang ditempati Australia dalam masalah ini. Setelah itu, mereka di terbangkan ke ibukota Canberra dan disambut oleh Sekretaris Pertahanan Australia Townly. ${ }^{56}$

Acara pertama menemui Presiden Menzies di kantornya di gedung DPR. Dia didampingi Laksamana Martadinata serta Duta Besar Saudi duduk di meja sidang Kabinet. Dia menjelaskan bahwa sejak Majapahit Irian Barat sudah termasuk wilayah Indonesia. Ratusan tahun penjajahan Belanda, Irian Barat telah satu bagian dari Hindia Belanda dan telah ikut bersama daerahdaerah lain senasib dan sepenanggungan memperjuangkan kemerdekaan

52 Abdul Haris Nasution. 67.

53 Abdul Haris Nasution. 71.

${ }^{54}$ Abdul Haris Nasution. 85.

55 Abdul Haris Nasution. 86.

56 Nieuw Guinea Koerir, "Overleg over Nieuw Guinea in Canberra Nasution verlangt een duldelijk antwoord van Australie: Australisch standpunt nog niet uiteengezet," 19 April 1961, 2. 
yang puncaknya adalah Proklamasi Kemerdekaan 1945 untuk seluruh bekas Hindia Belanda. Maka tidak mungkin pemerintah Indonesia melepaskan diri dari Proklamasi ini dan sikap Indonesia tidak akan berubah mengenai hal ini. Menzies mempersilahkan menteri-menteri mengajukan pertanyaan. ${ }^{57}$

A. Nasution juga menyatakan bahwa tujuan utama kunjungannya adalah untuk membahas klaim Indonesia atas Irian Barat. Dia berharap bisa meyakinkan pemerintah Australia bahwa dukungannya terhadap Belanda harus diubah menjadi kebijakan yang setidak-tidaknya netral. Menzies menghargai Indonesia sebagai tetangga dan teman yang punya kepentingan yang sama termasuk kepentingan dalam perdamaian dan keamanan. Salah satunya adalah Irian Barat. Hanya saja Australia mengakui kedaulatan Belanda tetapi jika kasus ini diajukan ke Pengadilan Internasional dan putusannya akan menguntungkan Indonesia maka Australia juga akan menghormati keputusan itu. Australia tidak siap memberi tekanan kepada Belanda untuk menegosiasi pengalihan kedaulatan dan penentuan nasib sendiri. Menzies juga memberi tahu A. Nasution bahwa Australia tidak memiliki persetujuan langsung atau tidak langsung dengan Belanda. ${ }^{58}$ Namun Menzies juga menekankan untuk tidak memakai cara kekerasan atas sengketa Indonesia-Belanda. Australia menentang cara itu apalagi di wilayah tetangga dekatnya. A. Nasution juga menegaskan lagi, sebagaimana di India dan Pakistan bahwa insiden-insiden di Irian Barat akan terus meningkat dan jika hal itu terus berjalan maka kemungkinannya akan meluas menjadi perang. ${ }^{59}$ Setelah tinggal di Sidney selama dua hari, A. Nasution dijadwalkan akan pergi ke Selandia Baru untuk kunjungan singkat, dimana setelah itu dia akan kembali ke Australia. ${ }^{60}$

Dia mendarat di airport Wellington dan disambut secara militer. Sorenya diadakan pertemuan dengan tokoh-tokoh masyarakat dan bisnis dimana Perdana Menteri Holyoak hadir. Acara A. Nasution di Serlandia Baru yaitu menghadiri acara makan malam dengan pimpinan Angkatan Perang Selandia Baru, KSAD sekaligus merangkap ketua GKS Jenderal Thornton, ke makam prajurit, berkunjung ke Parlemen, Perdana Menteri, dan

\footnotetext{
${ }^{57}$ Abdul Haris Nasution, Memenuhi Panggilan Tugas Jilid 5: Kenangan Masa Orde Lama. 1985, 90.

${ }^{58}$ Algemeen Handelsblad, "Nasution na gesprek met Menzies: 'Niet gelukkig' met het Australische standpunt," 27 April 1961, 3.

${ }^{59}$ Abdul Haris Nasution, Memenuhi Panggilan Tugas Jilid 5: Kenangan Masa Orde Lama, 1985, 91.

${ }^{60}$ Algemeen Handelsblad, .
} 
acara hari pahlawan. Setelah acara selesai, dia pergi ke Auckland. Barulah besoknya pamit ke Sidney dan malam harinya berangkat ke Manila. ${ }^{61}$

A. Nasution disambut di Manila oleh Menteri Pertahanan Santos serta para Kepala Staf Angkatan Perang beserta istri-istrinya. Acara militernya disana adalah berkunjung ke Akademi Militer di Baguio. Acara politik adalah mengunjungi Menteri Luar Negeri dan Presiden serta mengadakan konferensi pers. Sebagaimana di Australia pada kesempatan itu dia jelaskan tentang klaim Indonesia terhadap Irian Barat dan Perjuangan Indonesia untuk membebaskannya. Kepada pemerintah Filipina, dia meminta agar memboikot lalu lintas Belanda jika insiden di Perairan Irian Barat meluas menjadi perang menyeluru Dia tidak mendapatkan jawaban yang tegas tetapi mendapat respon yang bersimpati kepada perjuangan Indonesia. Dalam konferensi pers pun tidak terasa serangan-serangan seperti di Australia dan tidak ada wartawan-wartawan Barat. Dia meneruskan perjalanannya dari Filipina ke Bangkok dengan berhenti beberapa jam di airport Saigon. Disini tidak ada acara resmi namun Kepala Staf Angkatan Perang Thailand menjemput di pelabuhan udara. Besoknya kembali ke Jakarta. ${ }^{62}$

Pada Juni 1961, A. Nasution ke Moskow untuk penandatanganan kontrak kedua. Dia menggabungkan berbagai undangan dalam bidang Diplomasi TNI kebutuhan Pembebasan Irian Barat. Secara umum, rencananya untuk belajar. Dia merencanakan untuk berdiskusi dengan pimpinan politik dan militer di negara-negara Timur, Barat, dan non-blok mengenai pengalaman Menteri-menteri Pertahanan dan Kepala-kepala Staf Angkatan Perang negara lain dalam meninjau objek-objek militer baik di bidang pendidikan maupun operasional. Sedangkan secara khusus, rencananya adalah untuk menekan kontrak kedua di Kremlin (Moskow) dan satu dokumen kerjasama dengan Angkatan Perang Yugoslavia. ${ }^{63}$

Pada saat berkunjung ke Yugoslavia, A. Nasution bertukar pikiran dengan Menteri Pertahanan Yugoslavia, Jenderal Gosnyak. Dia mengatakan jika organisasi telah tertib dan teratur maka bisa cukup untuk mengendalikan bidang personalia dan keuangan karena dengan kedua saluran tersebut seluruh persoalan dapat diketahui dan diarahkan. ${ }^{64}$ Hal lain yang juga

61 Abdul Haris Nasution, Memenuhi Panggilan Tugas Jilid 5: Kenangan Masa Orde Lama. 89-100.

${ }^{62}$ Abdul Haris Nasution. 103-104.

${ }^{63}$ Abdul Haris Nasution. 125.

${ }^{64}$ Abdul Haris Nasution. 140. 
menarik adalah self management Yugoslavia. Kepentingan bersama yang dibela dan dikembangkan adalah partisipasi rakyat jelata secara luas. Komite-komite pembebasan nasional yang jadi pangkal tolak untuk mempertahankan negeri dan setelah perang untuk dikembalikan pada bidang sosial, ekonomi, dan politik. ${ }^{65}$

A. Nasution kemudian melanjutkan kunjungannya ke Prancis. Setelah melakukan pembicaraan dengan beberapa menteri khusus Menteri Pertahanan, dia menarik dua kesimpulan. Pertama, Prancis tidak ada ikatan politik dan militer dengan Belanda yang akan berkaitan kalau ada perang di Irian Barat. Kedua, Prancis akan tetap bersedia menjual alat-alat militer kepada Indonesia. Hanya saja dalam hal pembayaran minta kontan dan dalam beberapa hal angsuran sampai tiga tahun. ${ }^{66}$

Sewaktu di Jerman, A. Nasution bertukar pikiran dengan salah satu pimpinan intel Jerman, Jenderal Gehlen tentang fungsi dan posisi badan intel. ${ }^{67}$ Mengenai Irian Barat, Jerman tak punya ikatan apapun dengan Belanda. Mereka juga bersedia membantu Indonesia dalam pembelianpembelian senjata di Jerman dengan harga yang baik dan mengirim perwiraperwira Indonesia ke sekolah staf. Selain itu, pemerintah juga akan memberikan kesempatan pada A. Nasution untuk mengadakan konferensi pers seluas-luasnya dimana akan hadir wartawan Belanda. ${ }^{68}$

Pada kunjungannya ke London, A. Nasution menguraikan tugas Indonesia untuk membebaskan Irian Barat. Umumnya Inggris mengatakan bahwa hal itu bukan urusan Inggris tetapi mereka mengharapkan penyelesaian secara damai. $^{69}$ Pemerintah Inggris telah menjelaskan kepadanya bahwa hubungan dengan Belanda membuat tidak mungkin untuk mengubah posisi Inggris mengenai masalah Irian Barat. ${ }^{70}$

A. Nasution juga ke Mesir sebagai puncak acara. Dia mengharapkan jika terjadi perang Indonesia dengan Belanda hendaklah Mesir menutup udaranya bagi pesawat dan menutup Terusan Suez bagi kapal-kapal Belanda. ${ }^{71}$ Presiden Nasser merespon bahwa negara itu terikat pada suatu

\footnotetext{
${ }^{65}$ Abdul Haris Nasution. 142.

${ }^{66}$ Abdul Haris Nasution. 146.

${ }^{67}$ Abdul Haris Nasution. 151-152.

${ }^{68}$ Abdul Haris Nasution. 150.

${ }^{69}$ Abdul Haris Nasution. 159.

70 "Nasution had in London geen succes," Nieuw Guinea Koerier, 8 Juli 1961, 1.

${ }^{71}$ Abdul Haris Nasution, Memenuhi Panggilan Tugas Jilid 5: Kenangan Masa
} Orde Lama. 1985, 168. 
perjanjian internasional untuk menjamin lalu lintas internasional di Terusan Suez. Begitu juga ketika terjadi sengketa Irak dan Kuwait bersama Inggris, mereka tak bisa menutup Suez bagi Inggris. Namun ada jalan lain yaitu kaum buruh bisa memboikot kapal-kapal Belanda kalau memang diperlukan. Presiden ini juga berbicara mengenai Perang Suez 1956 dan pengalamannya. Sedangkan pertemuan dengan Menteri Pertahanan Hakim Amer, A. Nasution dapat menarik kesimpulan bahwa kelak Indonesia bisa mengandalkan bantuan dari Mesir. ${ }^{72}$

\section{Dampak}

\section{Pengambilalihan Perusahaan Belanda}

Beberapa perusahaan-perusahaan yang diambil alih seperti Perusahaan dagang Belanda terbesar di Indonesia Bormusij, Perusahaan Hoppenstedt, Internatio, bersama dengan kantor penumpang Rotterdam Lloyd, Guntzel Schumacher, agen perjalanan Nitour, dan perusahaan kontraktor Associatie. Selain itu, pengambilalihan ini juga terjadi di Jawa Timur dan Jawa Barat seperti sejumlah perusahaan dagang dan printer di Bandung dan Tasikmalaya. Bahkan di Bogor, telah diambilalih stasiun pengujian Algemeen Landbouw Syndicaat oleh para siswa. Di Semarang, para pemimpin perusahaan Belanda diharuskan untuk menghapus potret Putri Wihelmina dan Ratu Juliana dari kantor. Pemerintah juga melakukan pengusiran pada seniman-seniman asing. Selain itu, Kepala Staf Angkatan Darat Mayor Jenderal A. Nasution dan Menteri Keuangan Sutikno Slamet menempatkan kantor-kantor pusat bank-bank di Jakarta dan agen-agen di seluruh kepulauan di bawah pengawasan militer. Bank-bank ini juga akan melakukan aktivitasnya secara normal. $^{73}$ Selain itu, A. Nasution juga melarang perusahaan penerbangan Belanda Koninklijke Luchtvaart Maschappij (KLM) mengadakan aktivitas di Indonesia, larangan publikasi dan media berita Belanda serta pemulangan orang-orang Belanda yang tidak bermatapencarian tetap atau tidak diperlalukan lagi di Indonesia. ${ }^{74}$

Perusahaan yang telah dinasionalisasikan berjumlah \pm 700 buah dengan nilai 1.500 dollar. Pemerintah juga pindahkan pasaran bursa

${ }^{72}$ Abdul Haris Nasution. 170-172.

73 "Alle Nederlandse ondernemingen onder toezicht gesteld," Nieuwe Amsterdamsche Courant Algemeen Handelsblad, 9 Desember 1957, 1.

${ }^{74}$ Abdul Haris Nasution, Memenuhi Panggilan Tugas Jilid 5: Kenangan Masa Orde Lama., 1985, 282. 
tembakau dari negeri Belanda ke Bremen (Jerman Barat) untuk memutuskan sama sekali keuntungan-keuntungan ekonomis yang mungkin didapat Belanda dalam hubungan perdagangan dunia dengan Indonesia. Menyusul kemudian nasionalisasi milik warga negara Belanda yang tidak bergerak dan yang tidak terdapat di wilayah Indonesia. ${ }^{75}$

Efek yang langsung dirasakan oleh Belanda dalam hal ini adalah membawa mereka kehilangan suatu sumber penghasilan dari perusahaanperusahaannya yang ada di Indonesia baik yang berupa hak milik pemerintah Belanda maupun hak milik perorangan dimana perusahaan-perusahaan tersebut merupakan sumber penghasilan dan memberikan daya hidup bagi Belanda. Selain itu, tindakan ini bagi pemerintah Indonesia merupakan salah satu tindakan melemahkan ekonomi Belanda dan langsung menjadi sumber penghasilan pemerintah Republik Indonesia. ${ }^{76}$

Sikap Pemerintah Indonesia membekukan modal Belanda pun dijawab oleh Belanda dengan memperkuat kedudukan di Irian Barat serta meningkatkan anggaran pertahanannya. Pemerintah Indonesia pun menjawab tindakan Belanda dengan meningkatkan pertahanan di daerah perbatasan. Untuk lebih meningkatkan aksi-aksi Pembebasan Irian Barat maka dibentuklah Front Nasional Pembebasan Irian Barat (FNPIB) yang dibentuk dan diketuai oleh KSAD A. Nasution. ${ }^{77}$

\section{Mendirikan Front Nasional Pembebasan Irian Barat (FNPIB) dan Menjadi Ketuanya.}

A. Nasution sebagai Ketua Umum FNPIB mengintruksikan operasioperasi yaitu Operasi A untuk memulai infiltrasi-infiltrasi ke Irian Barat bagian Barat, Operasi B untuk menghimpun dan kaderisasi terhadap putraputra asal Irian Barat dan derah-daerah Maluku perbatasan terutama dari bekas Kesultanan Tidore yang dulunya membawahi Irian Barat, dan Operasi C yang ditugaskan pada Saudara Uyeng Suwargana dan para atase Militer yakni mempengaruhi sikap tokoh-tokoh Belanda di Nederland.

Operasi A adalah operasi infiltrasi yang bertujuan mengumpulkan keterangan militer dan membangkitkan semangat perlawanan rakyat Irian Barat serta membentuk kantong-kantong gerilya. Untuk memudahkan pelaksanaan infiltrasi dibentuk pos-pos konsentrasi pasukan yang tersebar

\footnotetext{
75 Abdul Haris Nasution. 283.

${ }^{76}$ Markas Besar Angkatan Darat Dinas Sejarah, Sejarah Perjuangan Trikora, 24.

${ }^{77}$ Markas Besar TNI, Pusat Sejarah, dan Tradisi TNI., 112.
} 
dari Morotai di utara sampai Letfuan di selatan, antara lain pulau-pulau Geser, Gebe, dan Ujir. Pasukan dari daerah diangkut oleh Angkatan Laut ke titik-titik rendevous yang telah ditentukan dan dari sini penyusupan dilakukan dalam kelompok-kelompok kecil menuju daratan Irian Barat dengan menggunakan kole-kole. Pos-pos konsentrasi intelegen: pos utara Gebe dipimpin oleh Mayor Amir Yudowinarno, pos selatan di Dobo dipimpin oleh Mayor Ali Murtopo. Pos komando berada di Pulau Ujir dimana pos ini punya komunikasi langsung dengan markas besar Angkatan Darat. Sedangkan Operasi B mempersiapkan satuan-satuan militer untuk merebut Irian Barat. Untuk keberhasilan tugas ini, Badan Kerjasama Sipil Khusus (BKSK) membentuk kader putra daerah yang berasal dari Irian Barat dan daerah perbatasan. Mereka dilatih untuk dijadikan infiltran yang akan disusupkan ke daratan Irian Barat. ${ }^{78}$

Operasi-operasi A dan B menghasilkan infiltrasi-infiltrasi yang pertama walaupun gagal yaitu operasi Pasukan Gerilya (PG) 100 yang tanggal 9 November 1960 dikirim rombongan pertama sejumlah 29 orang menuju Teluk Etna (Kaimana) dipimpin Letnan Antaribana. Menyusul gelombang kedua yang bertolak pada tanggal 14 September 1961 dengan mana PG-200 sejumlah 39 orang dipimpin oleh Letnan Jamaludin Nasution. Selain itu, Operasi C atau diplomasi senyap yang pelaksana utamanya adalah Uyeng Suwargana, pertama-tama dia mengadakan kontak-kontak di Nederland dengan pengusaha-pengusaha Belanda, kaum universitas seperti Prof. Duynstee, dan kawan-kawan, kaum politisi seperti bekas PM Drees, tokoh-tokoh gereja, dan tokoh-tokoh pers serta pemuda-pemuda Irian yang sekolah di Nederland. Para Atase di Eropa Barat seperti Kartakusumah di Paris, S. Parman di London, dan Panjaitan di Bonn merupakan pendukung usaha ini. ${ }^{79}$ Diplomasi senyap ini juga ikut berhasil mengadakan kontakkontak pribadi dengan tokoh-tokoh di Washington dimana yang terpenting adalah dengan Prof. Rostov, seorang penasihat utama dari Presiden Kennedy. ${ }^{80}$ Pembicaraan inilah yang telah mengubah sikap Amerika yang semula berpihak kepada Belanda menjadi berpihak kepada Indonesia. Dengan adanya campur tangan pemerintah Amerika ini, puncaknya terjadi perundingan RI-Belanda yang dimediasi oleh PBB di New York pada 15

\footnotetext{
78 Markas Besar TNI. 113.

79 Abdul Haris Nasution, Op cit., 1985, 76.

80 Abdul Haris Nasution. 77.
} 
Agustus 1962. Pada tanggal 1 januari 1963, bendera merah putih berkibar di Irian berdampingan dengan bendera PBB sedangkan bendera Belanda diturunkan. Sampai akhirnya Mei 1963, secara resmi PBB menyerahkan wilayah Irian Barat kepada Indonesia. ${ }^{81}$

\section{Diplomasi TNI}

Indonesia mendapat bantuan senjata dari Uni Soviet dalam rangka Perjuangan Pembebasan Irian Barat untuk melawan Belanda. Yang terbesar adalah untuk AL yang dulunya telah disetujui di Uni Soviet termasuk 12 kapal selam, belasan kapal roket cepat, pesawat-pesawat AL, helikopterhelikopter, dan peralatan berat amphibi untuk KKO lebih kurang 3 resimen. Untuk AU, Indonesia memesan pesawat-pesawat MIG 21, Ilyusin 28, TU-16 (pesawat yang diinginkan Soekarno yang nantinya dipakai untuk membawa bom dari Jawa ke Irian Barat dan dapat terbang kembali ke Jawa), dan pesawat-pesawat angkut antonov beserta 3 satuan pertahanan udara dengan roket beserta radarnya. ${ }^{82}$

Indonesia pun sontak menjadi negara dengan kekuatan militer yang disegani di kawasan sekitarnya. Tujuan diplomasi Indonesia dengan unjuk kekuatan ini dianggap menciptakan a sense of crisis yang mengarah ke konflik yang tak dapat dielakkan. Ancaman serbuan militer Indonesia ke Irian Barat pun menjadi senjata psikologis yang amat kuat bagi Belanda. ${ }^{83}$ Sementara itu, pihak Uni Soviet yang membantu Indonesia dalam persenjataan pun menjamin kelanjutan suplai material akan berjalan terus jika seandainya harus terjadi perang dan personalnya akan tetap membantu Indonesia. Menurut A. Nasution, peranan Uni Soviet itu membuat Amerika Serikat terdorong untuk menekan Belanda agar mundur kemudian pada tahun 1962 dalam Plan Bunker. Presiden Kennedy mengirim surat kepada PM Belanda Jan de Quay untuk menerimanya. Menurutnya jika perundingan gagal maka akan terjadi perang dan Belanda tak mungkin memenangkan perang itu. Bahkan dengan itu, komunislah (terutama Uni Soviet) yang akan mendapat angin di Asia Tenggara. ${ }^{84}$ Dalam hal ini, Kennedy melihat Indonesia sebagai negara yang secara signifikan penting sehingga perlu dicegah jangan sampai terhanyut ke Blok Komunis. Apalagi dia juga mengetahui kondisi ekonomi Indonesia yang memburuk akan dimanfaatkan

\footnotetext{
${ }^{81}$ Dinas Sejarah Angkatan Darat, 119.

${ }^{82}$ Dinas Sejarah Angkatan Darat. 57.

${ }^{83}$ Beny Adrian., 7-8.

${ }^{84}$ Abdul Haris Nasution, 1985, 324.
} 
oleh PKI (Partai Komunis Indonesia) yang saat itu sudah menjadi kekuatan yang diperhitungkan dalam perpolitikan Indonesia. Bahkan PKI termasuk partai terbesar di luar Blok Timur. Amerika khawatir bila Komunis sampai unggul di Indonesia maka akan membahayakan posisi Blok Barat. Karena itu Kennedy ingin mencegah timbulnya perang antara Indonesia dengan Belanda. Sebab jika sampai pecah maka hanya akan menimbulkan polarisasi situasi. Blok Barat boleh jadi akan membantu Belanda dan sebaliknya Indonesia pun pasti didukung oleh Blok Timur. Selanjutnya, konfrontasi ini akan berubah menjadi adu kekuatan antara suatu kekuatan kolonial yang disokong AS atau Blok Barat dengan sebuah negara Dunia Ketiga yang didukung kelompok Non Blok dan Blok Timur. Karenanya dengan segala usaha, polarisasai seperti itu harus dicegah jangan sampai terjadi. Lebihlebih AS pun mulai terlibat di Laos dan Vietnam. Kennedy tidak mau terlilit dalam senseless engagement di Irian Barat. Dia sendiri bahkan mengistilahkannya dengan Pointless Colonial Issue. ${ }^{85}$

Perjalanan atau misi Menteri Keamanan Nasional A. Nasution ke luar negeri membuat Indonesia bisa memperhitungkan bahwa Australia akan tetap bersikap keras terhadap Indonesia tanpa melepaskan hubungan baiknya tetapi sebaliknya kecil kemungkinan bahwa Australia akan melibatkan dirinya dalam sengketa bersenjata dengan Indonesia karena Australia tidak mau mengambil resiko timbulnya Perang Dunia.

Amerika dalam rangka NATO, SEATO, dan ANZUS akan tetap membantu Belanda secara tertutup baik berupa bantuan senjata maupun pemberian fasilitas-fasilitas pengangkutan (pangkalan-pangkalan) serta menggunakan kekuasaannya agar sukarelawan-sukarelawan negara satelitnya seperti Taiwan dan Korea Selatan memberikan bantuannya kepada Belanda. Demikian pun Inggris sebagaimana Amerika Serikat akan melakukan tindakan sabotatif melalui investasi-investasi modalnya dan jasajasa yang ada di Indonesia seperti perminyakan, perkebunan, dan pengangkutan-pengangkutan.

Dari negara-negara seperti Thailand dan Filipina sedikit harapan akan memberikan bantuan kepada Indonesia. Bahkan sebaliknya, akan memberikan fasilitas-fasilitas penggunaan pangkalan-pangkalannya kepada pihak Belanda bila Belanda menggunakan fool-route ke Irian Barat. Pertimbangan mereka adalah ekonomis sifatnya. Selain itu, bantuan-bantuan

\footnotetext{
${ }^{85}$ Beny Adrian. 10-11.
} 
negara sosialis yang diberikan kepada Indonesia baik secara politis atau militer-ekonomis diperhitungkan oleh mereka dengan tujuan menarik simpati negara-negara Asia-Afrika dalam perjuangan melawan imperialisme dan mengalihkan perhatian SEATO dari persoalan-persoalan di Laos dan Vietnam ke Irian Barat agar dengan demikian membuka pintu bagi gerakan Komunis ke Selatan. Sedangkan dari negara-negara non-allignment hanya akan dapat Indonesia harapkan bantuan moril atau semangat sesuai dengan jiwa Konferensi Tingkat Tinggi (KTT) Beograd dan negara-negara seperti Mesir dan India akan menutup pangkalan-pangkalan bagi lalu lintas pengangkutan tentara serta alat-alat militer ke Irian Barat. ${ }^{86}$

\section{Kesimpulan}

Abdul Haris Nasution adalah salah satu tokoh militer yang banyak menduduki jabatan penting pemerintahan. Walaupun pernah sekolah di HIK, keinginan militer dan politiknya semakin kuat sampai dia masuk Akademi Militer Bandung dan dididik oleh Belanda. Dari sini, dia mulai mendapat pangkat dan berturut-turut menduduki jabatan penting pemerintahan sampai pensiun. Adapun peranannya dalam Pembebasan Irian Barat yaitu: pertama, rangka pengambilalihan perusahaan-perusahaan Belanda. Efek yang langsung dirasakan oleh Belanda dalam hal ini adalah membawa mereka kehilangan suatu sumber penghasilan dari perusahaan-perusahaannya yang ada di Indonesia dan melemahkan ekonomi Belanda. Kedua, mendirikan Front Nasional Pembebasan Irian Barat (FNPIB) dan menjadi ketuanya. Sebagai Ketua Umum, dia mengintruksikan Operasi A untuk memulai infiltrasi-infiltrasi ke Irian Barat bagian Barat, Operasi B untuk menghimpun dan kaderisasi terhadap putra-putra asal Irian Barat dan daerah-daerah Maluku perbatasan terutama dari bekas Kesultanan Tidore yang dulunya membawahi Irian Barat, dan Operasi $\mathrm{C}$ yang ditugaskan pada Uyeng Suwargana dan para atase Militer yakni mempengaruhi sikap tokoh-tokoh Belanda di Nederland. Ketiga, diplomasi TNI dalam pembelian senjata dan misi ke luar negeri untuk mendengar respon negara-negara lain mengenai Irian Barat.

${ }^{86}$ Departemen Angkatan Darat Staf Umum Angkatan Darat-I, Perkembangan Perjuangan RI dalam Usaha Pembebsan Irian Barat, 1962, 3-4. 
Peran Abdul Haris Nasution dalam Pembebasan Irian Barat (1957-1962)| Devi Nurhikmi, Ajid Thohir, dan Samsudin

\section{Daftar Sumber}

\section{Arsip/Dokumen}

Departemen Angkatan Darat Staf Umum Angkatan Darat-I, Perkembangan Perjuangan RI dalam Usaha Pembebasan Irian Barat, 1962.

Front Nasional Pembebasan Irian Barat Pusat BKS Khusus, Laporan Bulanan B1. IX-158, 1960.

Kepala Staf Angkatan Darat/Penguasa Perang Pusat/Ketua Umum FNPIB Pusat A. Nasution, Keputusan Penguasa Perang Pusat No. Kpts/Peperpu/0345/1958 tentang Peraturan Rumah Tangga Front Nasional Pembebasan Irian Barat (Jakarta, 1959)

Keputusan Menteri Pertama RI No.485/MP/1959, Ketentuan-ketentuan tentang Kebijaksanaan Pemerintah terhadap Perusahaanperusahaan milik Belanda (Jakarta, 1959)

Markas Besar Angkatan Darat Dinas Sejarah, Sejarah Perjuangan Trikora (Dinas Sejarah Angkatan Darat, 2018)

\section{Buku}

Adrian, Beny. 2014. 52 Tahun Infiltrasi PGT di Irian Barat. Jakarta: Gramedia.

Dinas Sejarah Angkatan Darat. 2009. Biografi Jenderal Besar DR. A. Nasution: Perjalanan Hidup dan Pengabdiannya. Dinas Sejarah Angkatan Darat.

Kuntowijoyo. 2013. Pengantar Ilmu Sejara Yogyakarta: Penerbit Tara Wacana.

Markas Besar TNI, Pusat Sejarah, dan Tradisi TNI. 2000. Sejarah TNI Jilid 3 1960-1965. Jakarta: Markas Besar TNI, Pusat Sejarah, dan Tradisi TNI.

Nasution, Abdul Haris. 1997. Bisikan Nurani Seorang Jenderal: Kumpulan Wawancara dengan Media Massa, ed. oleh Drs. Bakri A. G. Tianlean. Bandung: Penerbit Mizan.

. 1984. Memenuhi Panggilan Tugas Jilid 1: Kenangan Masa Muda. Jakarta: PT. Gunung Agung. . 1984. Memenuhi Panggilan Tugas Jilid 4: Masa Pancaroba II. Jakarta: PT. Gunung Agung. . 1985. Memenuhi Panggilan Tugas Jilid 5: Kenangan Masa Orde 
Peran Abdul Haris Nasution dalam Pembebasan Irian Barat (1957-1962)| Devi Nurhikmi, Ajid Thohir, dan Samsudin

Lama. Jakarta: PT. Gunung Agung.

Poesponegoro, Marwati Djoened dan Nugroho Notosusanto. 1990. Sejarah Nasional Indonesia VI. Jakarta: Balai Pustaka.

Santoso Az, Lukman. 2014. Jenderal-jenderal yang Mempengaruhi Sejarah

Dunia. Yogyakarta: Penerbit Palapa.

Simanjuntak, P. N. 2003. Kabinet-kabinet Republik Indonesia dari Awal Kemerdekaan sampai Reformasi. Jakarta: Djambatan.

Sulasman. 2014. Metodologi Penelitian Sejara Bandung: Pustaka Setia.

Suryanegara, Ahmad Mansur. 2016. Api Sejarah 2. Bandung: Surya Dinasti.

Tim Narasi. 2009. 100 Tokoh yang Mengubah Indonesia. Yogyakarta: Penerbit Narasi.

\section{Koran}

Algemeen Handelsblad, "Nasution na gesprek met Menzies: 'Niet gelukkig' met het Australische standpunt," 27 April 1961.

"Alle Nederlandse ondernemingen onder toezicht gesteld," dalam Nieuwe Amsterdamsche Courant Algemeen Handelsblad, 9 Desember 1957.

"Nasution had in London geen succes," dalam Nieuw Guinea Koerier, 8 Juli 1961.

"Nasution over Nieuw Guinea," dalam Friese Koerir, 29 Februari 1960.

Nieuw Guinea Koerir, "Overleg over Nieuw Guinea in Canberra Nasution verlangt een duldelijk antwoord van Australie: Australisch standpunt nog niet uiteengezet," 19 April 1961. 
Peran Abdul Haris Nasution dalam Pembebasan Irian Barat (1957-1962)| Devi Nurhikmi, Ajid Thohir, dan Samsudin 